\title{
Interactive comment on "Socio-Hydrologic Modeling of the Dynamics of Cooperation in the Transboundary Lancang-Mekong River" by You Lu et al.
}

\section{Gopal Penny (Referee)}

gpenny@nd.edu

Received and published: 25 September 2020

Lu et al., 2020. HESSD.

\section{General comments}

The authors present a socio-hydrological model of cooperation in transboundary watersheds, using the Lancang-Mekong river basin as a case study. In the model (and case study), upstream countries seek to develop the river for hydropower generation whereas downstream countries rely on river flow for agriculture and fisheries. Cooperation in the model is realized when upstream riparian countries adjust reservoir

Printer-friendly version

Discussion paper 
operations and forgo economic gains for the benefit of downstream riparian countries. This cooperation occurs in response to "cooperation demand" of downstream countries, which increases when ecosystem services decrease in these countries. The essential feedback within the model (i.e., cooperation) also depends on the disposition of the upstream riparian to their downstream partners, broadly representing the geopolitical relationship between countries. Cleverly, reservoir operation varies between the ideal operation for upstream countries (optimize hydropower) and downstream countries (e.g., optimize agricultural production), which allows cooperation to be quantified as a value between 0 and 1 .

The manuscript focuses on model development and validation rather than hypothesis testing. The novelty of the manuscript therefore rests primarily in the quantitative formulation of transboundary cooperation, including a novel and parsimonious representation of transboundary politics and decision making. This question is of great concern to understanding long-term streamflow trajectories in transboundary basins. The hydrological portion of the model is rigorously validated, and the economics portion of the model is based on established models. The cooperative and political components of the model are also based on published literature. However, given the novelty of this aspect of the model and importance to the nonlinearity / feedback mechanism within the model, the cooperative aspects merit additional consideration within the manuscript, as I describe in "Specific comments".

Overall the manuscript is clearly written and presents an important and novel contribution to better understand and model cooperation in transboundary basins. My primary concern relates to parameter selection and calibration, especially those parameters pertaining to cooperation (as I describe below).

Specific comments

Although the cooperation portion of the model appears to be designed in a manner that is consistent with cooperation in the Mekong, parameterization and validation of

Printer-friendly version

Discussion paper
Interactive

comment 
this component of the model is given relatively little attention. This raises the question of whether or not the (geo)politics represented in the model (specifically, variables $P$, $\mathrm{s}$, and $\mathrm{B} \_\mathrm{h}, \mathrm{FC}$ ) can be parameterized a priori, or if they need to be calibrated a posteriori to cooperation. The method of selecting these variables should be more clearly described with within the manuscript (beyond a statement of their values on lines 609613). This information is essential to understand how the model could be used to understand transboundary cooperation beyond the Mekong, and along those lines it would be helpful for the authors to more clearly detail how they envision future applications of the model would support (and help understand) transboundary cooperation in other regions. This would also give more weight to the statement (abstract, lines 42-44) that "the socio-hydrological model used here provides a useful new framework to investigate and improve transboundary water management elsewhere."

The dynamics of cooperation within the Mekong have been described qualitatively in other papers referenced in the manuscript. Indeed, these papers give confidence to the model as the authors demonstrate that the model is consistent with this qualitative narrative, both in terms of formulation and outcome. However, this raises the question of how the model generates additional insights about cooperation in the Mekong basin beyond what has already been described elsewhere. This particular aspect should be clarified within the manuscript âĂŤ i.e., what specific insights about transboundary cooperation has the model generated that were not apparent from previous research?

An additional aspect of the manuscript that was novel was the use of Lexis-Nexis sentiment analysis, and I suggest this aspect be given more attention in the introduction (at present, it seems downplayed).

\section{Technical corrections}

The second sentence of the abstract seems informal and lacks precision, and I suggest replacing "etc." with either additional examples or more precise phrasing.

Parameter selection would be more appropriate in the model development section, 
opposed to the results section (e.g., lines 609-613).

Lines 625 - 638 would fit better in the Model section, perhaps as a validation subsection.

Subsections in Section 2 are numbered incorrectly as 3.1, 3.2, etc (should be 2.1, 2.2, etc).

Using "iff" as a variable name is confusing, because in mathematics notation it means "if and only if" (line 402)

On the first read it was a bit confusing to have two equivalent variables for cooperation, delta2 and $\mathrm{C}$. Perhaps it would be helpful to include a note in figure 3 that the two are equal.

Interactive comment on Hydrol. Earth Syst. Sci. Discuss., https://doi.org/10.5194/hess-2020$388,2020$. 